\title{
Coregulatory protein-orphan nuclear receptor interactions in the human adrenal cortex
}

\author{
Sinead $\mathbf{N}$ Kelly, T Joseph McKenna ${ }^{1}$ and Leonie $\mathbf{S}$ Young \\ Department of Surgery, Conway Institute of Biomolecular and Biomedical Research, University College Dublin, Belfield, Dublin 4, Ireland \\ ${ }^{1}$ Department of Endocrinology and Diabetes Mellitus, St Vincent's University Hospital, Elm Park, Dublin, Ireland \\ (Requests for offprints should be addressed to L S Young; Email: Leonie.Young@ucd.ie)
}

\begin{abstract}
The capacity of the adrenal to produce steroids is controlled in part through the transcriptional regulation of steroid enzymes. The orphan nuclear receptor steroidogenic factor 1 (SF-1) is central to the transcriptional regulation of all steroid hydroxylase enzymes, whereas nur77 can preferentially regulate steroid enzyme genes relevant to cortisol production. We hypothesised that, in the presence of secretagogues, SF-1 and nur77 may differentially interact with coregulatory proteins in the human adrenal cortex. Both coregulatory proteins, steroid receptor coactivator (SRC-1) and silencing mediator for retinoid and thyroid hormones (SMRT), were found to be expressed in the zona fasciculata and reticularis in the human adrenal cortex, but were largely absent from the zona glomerulosa. Both coregulatory proteins were colocalised with SF-1 and nur77. In the H295R adrenal
\end{abstract}

tumour cell line, SF-1 and nur77 transcripts were increased in cells in the presence of forskolin, whereas nur77 mRNA was also induced with angiotensin II (AII). The coactivator SRC-1 mRNA was increased in the presence of both forskolin and AII. Forskolin induced recruitment of SRC-1 to the SF-1 response element and induced SRC-1-SF-1 interactions, whereas AII increased recruitment of SRC-1 to the nur77 response element and induced SRC-1-nur77 interactions. The corepressor SMRT interacted with SF-1 in the presence of AII and with nur77 in cells treated with forskolin. Orphan nuclear receptor-coregulatory protein interactions may have consequences for the regulation of key steroidogenic enzymes in the human adrenal cortex.

Journal of Endocrinology (2005) 186, 33-42

\section{Introduction}

In the human adrenal gland, adrenocorticotrophic hormone (ACTH) modulates both cortisol and adrenal androgen production, but there are, however, conditions where the production of these steroids becomes divergent (McKenna \& Cunningham 1991). This divergence is illustrated physiologically at the adrenarche and adrenopause and in pathophysiological situations such as polycystic ovarian syndrome (PCOS) and anorexia nervosa (Winterer et al. 1985, McKenna \& Cunningham 1991).

Steroid production of cortisol and androgens require the concerted action of a related group of cytochrome P450 steroid hydroxylase enzymes that convert the precursor cholesterol to biologically active products (Parker \& Schimmer 1994). 21-Hydroxylase (CYP21) regulates cortisol and aldosterone production, whereas 17-hydroxylase/ 17,20-lyase (CYP17) is primarily concerned with androgen production. We have recently shown that modulation of these key steroidogenic hydroxylase enzymes is controlled, at least in part, by ACTH and angiotensin II (AII), signalling through specific transcription factors such as steroidogenic factor-1 (SF-1) and nur77. We have previously demonstrated that nur77 may preferentially regulate steroid enzyme genes relevant to cortisol production and thereby regulate differential cortisol and adrenal androgen production (Kelly et al. 2004).

Central to the efficient orchestration of events which lead to transcriptional activation of steroid enzyme genes is the recruitment by nuclear receptors of coregulators (coactivators and corepressors) which interact with and effect transactivation (McKenna et al. 1999a). It has been suggested that cofactors serve as a bridging apparatus between the nuclear receptor and the transcriptional machinery. Coactivator recruitment leads to the acetylation of histones, which destabilises nucleosomes and relieves transcriptional repression by allowing transcription factors access to recognition elements on the target gene promoter (McKenna et al. 1999b, Sterner \& Berger 2000). On the contrary, corepressor binding results in recruitment of histone deacetylases, which stabilises the repressed state and inhibits gene transcription (Xu et al. 1999). A growing number of coregulatory proteins have been identified as mediators and modulators of steroid receptor 
signalling. The most widely studied coactivators are steroid receptor coactivators (SRCs), members of the p160 family, which are critical components of the signalling pathway (Spencer et al. 1997). Members of the SRC family include SRC-1, SRC-2, transcription intermediary factor 2 (TIF2)/glutamate receptor interacting protein-1) and SRC-3 (activator of thyroid and retinoic acid receptor (ACTR), AIB-I, CBP interacting protein). Conversely, corepressors such as silencing mediator for retinoid and thyroid hormone receptor (SMRT) interact strongly with nuclear receptors under basal conditions and this interaction is thought to be destabilised in the presence of a ligand. Thus, SMRT constituently represses transcription (Horlein et al. 1995, Horwitz et al. 1996).

Coregulatory proteins would appear to play a role in endocrine disorders and tumours. Differential expression of endometrial steroid receptor coregulatory proteins has been shown to play a role in the regulation of endometrium remodelling (Wieser et al. 2002). Overexpression of coregulatory proteins in PCOS patients is thought to be associated with poor reproductive performance and increased incidence of endometrium hyperplasia and cancer (Gregory et al. 2002). The coregulators SRC-1 and SMRT have been shown to associate/interact with SF-1 and nur77. SRC-1 has been shown to potentiate the activity of SF-1 (Ito et al. 1998) and has been shown to bind to nur77 (Sohn et al. 2001, Maira et al. 2003). The corepressor SMRT may interact indirectly with SF-1 and has been shown to interact directly with nur77 to cause inhibition of gene transcription (Sohn et al. 2001). Variations in the activity of coregulatory proteins are predicted to lead to changes in hormone responsiveness (Auger et al. 2000, Xu et al. 2000). However, to date, no clear role for coregulatory proteins in adrenal steroidogenesis has been defined.

A balance between transcriptional activation and repression is essential in the control of adrenocortical hormone biosynthesis. Expression and regulation of specific transcription factors and coregulatory proteins may therefore be central to the dissociation of adrenal androgens and cortisol seen in physiological and pathophysiological conditions. We have investigated the expression and differential interaction of coactivator SRC-1 and corepressor SMRT with transcription factors SF-1 and nur77 in the human adrenal gland and adrenal cell line under the influence of ACTH and AII.

\section{Materials and Methods}

\section{Preparation and stimulation of cell suspensions and H295R} cells

The human adrenal tumour cell line, H295R, was obtained from the American Type Culture Collection (Rockville, MD, USA). Cells were maintained in supplemented RPMI $(5 \mu \mathrm{g} / \mathrm{ml}$ insulin, $10 \mu \mathrm{g} / \mathrm{ml}$ transferin,
$30 \mathrm{nM}$ sodium selinite, $10 \mathrm{nM}$ hydrocortisone, $10 \mathrm{nM}$ $\beta$-oestradiol, $10 \mathrm{mM}$ Hepes, $2 \mathrm{mM}$ glutamine and $2 \%$ foetal calf serum (w/v)) and grown in $75 \mathrm{~cm}^{2}$ flasks at $37^{\circ} \mathrm{C}$ under an atmosphere of $5 \% \mathrm{CO}_{2}$. Cells were incubated for $2,16,20$ or $24 \mathrm{~h}$ in the presence or absence of forskolin $\left(10^{-7} \mathrm{M}\right)$ and AII $\left(10^{-7} \mathrm{M}\right)$ in serum-free medium. The cells were removed and stored for protein or RNA extraction.

\section{Immunohistochemistry}

Following ethical and donor approval, human adrenal glands were surgically removed at the time of resection for renal transplantation. An immunohistochemical technique was employed for the identification and localisation of SRC-1 and SMR T in human adrenal gland cryo-sections. Adrenal cryo-sections were air dried and fixed in absolute alcohol $(7 \mu \mathrm{m})$, immunoblocked in serum for $90 \mathrm{~min}$ and incubated with a primary goat anti-human SRC-1 $(2 \mu \mathrm{g} / \mathrm{ml})$ (sc-6097; Santa Cruz Biotechnology Inc., Santa Cruz, CA, USA) and goat anti-human SMRT $(2 \mu \mathrm{g} / \mathrm{ml})$ (sc-1612; Santa Cruz Biotechnology Inc.) for $1 \mathrm{~h}$ at room temperature and subsequently with anti-goat horseradish peroxidase secondary antibody (1:2000) for $1 \mathrm{~h}$ at room temperature. Sections were developed in $3,3^{\prime}-$ diaminobenzidine tetrahydrochloride for $7 \mathrm{~min}$ and counterstained with Mayer's haematoxylin. Negative controls were performed where the primary antibody was substituted with matched IgG controls (Dako, Glostrup, Denmark) and no staining was detected.

\section{Immunofluorescence}

Adrenal gland cryosections were prepared as above and incubated in goat serum for $60 \mathrm{~min}$. Rabbit anti-human $\mathrm{SF}-1(50 \mu \mathrm{g} / \mathrm{ml}$ in $10 \%$ human serum; PA1-800; Affinity Bioreagents, Golden, CO, USA) or rabbit anti-human nur77 $(50 \mu \mathrm{g} / \mathrm{ml}$ in 10\% human serum; sc-5569; Sigma, Poole, Dorset, UK) were placed on each slide for $90 \mathrm{~min}$. The sections were rinsed in phosphate-buffered saline (PBS) and incubated with the corresponding secondary tetramethylrhodamine isothiocyanate chloride-conjugated antibody (1:100) for $60 \mathrm{~min}$. Sections were rinsed in PBS, blocked in rabbit serum for $90 \mathrm{~min}$ and washed with PBS. Each slide was incubated with either goat anti-human SRC-1 (sc-6097; Santa Cruz Biotechnology Inc.) or goat anti-human SMRT (sc-1612; Santa Cruz Biotechnology Inc.) (both $10 \mu \mathrm{g} / \mathrm{ml}$ in $10 \%$ human serum) for $90 \mathrm{~min}$, followed by a wash in PBS. The slides were incubated with the corresponding fluorescein isothiocyanate-conjugated antibody (1:100) for $60 \mathrm{~min}$. Sections were rinsed in PBS and mounted using fluorescent mounting media (Dako). Sections were examined under fluorescent light. Negative controls were performed where the primary antibody was substituted with a matched IgG control and no staining was detected. Sections were counterstained with diamidino-2phenylindole (DAPI) to identify the nucleus. 


\section{Protein extraction and quantification}

Total protein (whole cell lysates) was extracted from H295R cells by incubation in lysis buffer (PBS, 1\% Igepal and $0.5 \%$ deoxycholic acid) supplemented with phenylmethylsulphonyl fluoride $(10 \mu \mathrm{g} / \mathrm{ml})$ and apoprotinin $(1.5 \mu \mathrm{g} / \mathrm{ml})$ for $30 \mathrm{~min}$. Protein was quantified using the BCA assay kit (Pierce Chemicals Co., Rockford, IL, USA). Cytoplasmic and nuclear protein extractions of H295R were performed using NE-PER nuclear and cytoplasmic extraction kits (Pierce Chemicals Co.) according to the manufacturer's instructions.

\section{Northern blot analysis}

Total RNA was isolated from stimulated H295R cells using RNeasy extraction kit (Qiagen, Crawley, W Sussex, $\mathrm{UK}$ ) at specific times after treatment. RNA was quantified by u.v. absorption. RNA $(10 \mu \mathrm{g})$ was electrophoresed on a standard Northern gel and transferred to a nylon membrane (Biorad, Hercules, CA, USA) by pressure blotting overnight and incubated for $3 \mathrm{~h}$ at $80{ }^{\circ} \mathrm{C}$.

Prehybridization was carried out at $42{ }^{\circ} \mathrm{C}$ for $3 \mathrm{~h}$ in a final buffer composition of $45 \%$ formamide, $4 \times \mathrm{SSC}$, $0 \cdot 1 \mathrm{M}$ NaPhosphate, $0 \cdot 1 \%$ napyrophosphate, $0 \cdot 1 \%$ SDS and $250 \mu \mathrm{g} / \mathrm{ml}$ herring sperm. Hybridisations were performed in the same buffer at $42{ }^{\circ} \mathrm{C}$ overnight with a DNA probe for SF-1 (forward 5'-AGATGACGCTGCA GAACTG-3', reverse 5'-GAGTCCTCTTTTGGTTG CGG-3') and nur77 (forward 5'-ATACACCCGTGA CCTCAACCA-3', reverse 5'-GAGGAGTGAAGGGA CCAGGC-3') amplified by PCR and antisense probes to SRC-1 (IMAGE clone; PT7T3D-PACI; Invitrogen) and SMRT (Professor R M Evans, Salk Institute for Biological Studies, La Jolla, CA, USA) using $\left[\alpha-{ }^{32} \mathrm{P}\right] \mathrm{dCTP}$ and a random primer labelling system (Promega, Madison, WI, USA). The blots were then washed in $2 \times \mathrm{SSC}$ containing $0.5 \% \mathrm{SDS}$ at room temperature for $10 \mathrm{~min}$, at $42{ }^{\circ} \mathrm{C}$ for $10 \mathrm{~min}$ and at $55^{\circ} \mathrm{C}$ for $10 \mathrm{~min}$ before they were exposed to film at $-80{ }^{\circ} \mathrm{C}$ using intensifying screens. Results were assessed directly by Eagle Eye (Stratgene, La Jolla, CA, USA) analysis and compared with levels of 28S RNA in the same lane.

\section{Electrophoretic mobility shift assays (EMSA)}

Nuclear protein extracts were prepared as described above. For EMSA, $5 \mu \mathrm{g}$ nuclear extract was incubated for $20 \mathrm{~min}$ in the presence of $20 \mathrm{mM}$ Hepes, pH 7.9, $5 \mathrm{mM}$ $\mathrm{MgCl}_{2}, 20 \%$ glycerol, $100 \mathrm{mM} \mathrm{KCl}, 0 \cdot 2 \mathrm{mM}$ EDTA, 8\% Ficoll, $600 \mathrm{mM} \mathrm{KCl,} 500 \mathrm{ng} / \mu \mathrm{l}$ poly deoxyinosinicdeoxycytidylic acid, $50 \mathrm{mM}$ dithiothreitol and $\left[\alpha-{ }^{32} \mathrm{P}\right] \mathrm{dCTP}-$ labelled double-stranded oligonucleotide. For supershift experiments, antibodies against SF-1 (PA1800; Affinity Bioreagents), nur77 (sc-7014X; Santa Cruz Biotechnology Inc.), SRC-1 (sc-6097X; Santa Cruz
Biotechnology Inc.) and SMRT (sc-1612X; Santa Cruz Biotechnology Inc.) were added following the initial 20-min incubation, then incubated for a further $20 \mathrm{~min}$. The samples were electrophoresed through a 5.5\% nondenaturing polyacrylamide gel in $0.5 \times$ Tris borate-EDTA buffer. For competition studies, the reaction was performed as described with $50 \times$ molar excess of unlabelled probe. The following oligonucleotides were designed to incorporate the native human CYP21 (for nur77 binding) and CYP17 (for SF-1 binding) promoter sequences: SF-1 (CYP17, NM_000102) 5'-TTGCAAGCCTTGACTCC TGAGCCCAGATACCA-3' and nur77 (CYP21, NM_000500) 5'-CTGGATGCAGGAAAAAGGTCAG GGTTGCACTT-3'. The consensus sequence for the SF-1- and nur77-binding elements is underlined (Wilson et al. 1991, Hanley et al. 2001).

\section{Immunoprecipitation}

Complex formation between coregulators and SF-1 and Nur77 was examined by using H295R cell lysates. Whole cell lysates were prepared as described above. Lysate $(100 \mu \mathrm{g})$ was immunoprecipitated with $2 \mu \mathrm{g}$ of either anti-SRC-1 (sc-6097; Santa Cruz Biotechnology Inc.) or anti-SMRT (sc-1612; Santa Cruz Biotechnology Inc.) for $60 \mathrm{~min}$ at $4{ }^{\circ} \mathrm{C}$. The precipitates were collected for $1 \mathrm{~h}$ on protein A/G-agarose (Santa Cruz Biotechnology Inc.). After washing with RIPA buffer (PBS, 1\% lgepal and $0.5 \%$ deoxycholic acid), precipitates were resuspended in Laemmli SDS sample buffer and resolved in $12 \%$ SDS-PAGE. After transfer to nitrocellulose, the proteins were probed with either anti-SF-1 (PA1-800; Affinity Bioreagents) or anti-nur77 (sc-7014; Santa Cruz Biotechnology Inc.), followed by the corresponding peroxidaseconjugated secondary antibody (1:2000). Labelled bands were detected using chemiluminescence (Santa Cruz Biotechnology Inc.).

\section{Chemicals}

All chemicals were obtained from Sigma unless otherwise specified.

\section{Results}

\section{Localisation of SRC-1 and SMRT in human adrenal gland}

SRC-1 and SMRT were localised within the human adrenal gland using immunohistochemistry. Strong positive staining was detected for SRC-1 and SMRT in the zona fasciculata and zona reticularis but was largely absent from the zona glomerulosa. Both coregulatory proteins were found to be expressed principally in the nuclei of adrenal cells. Specific staining was absent when the primary antibody was substituted with matched IgG (Fig. 1). 
$\boldsymbol{A}$

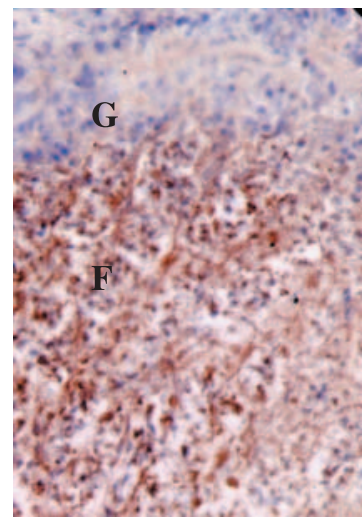

C

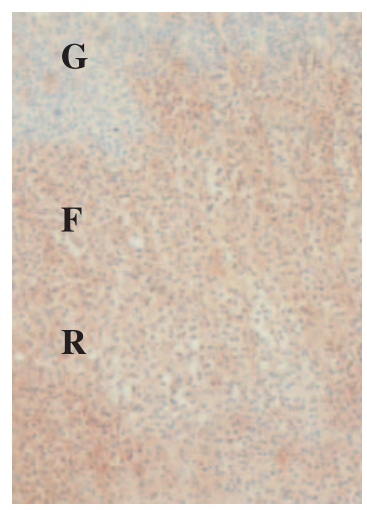

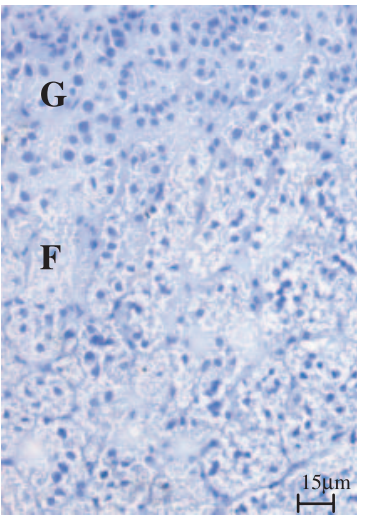

$\boldsymbol{B}$
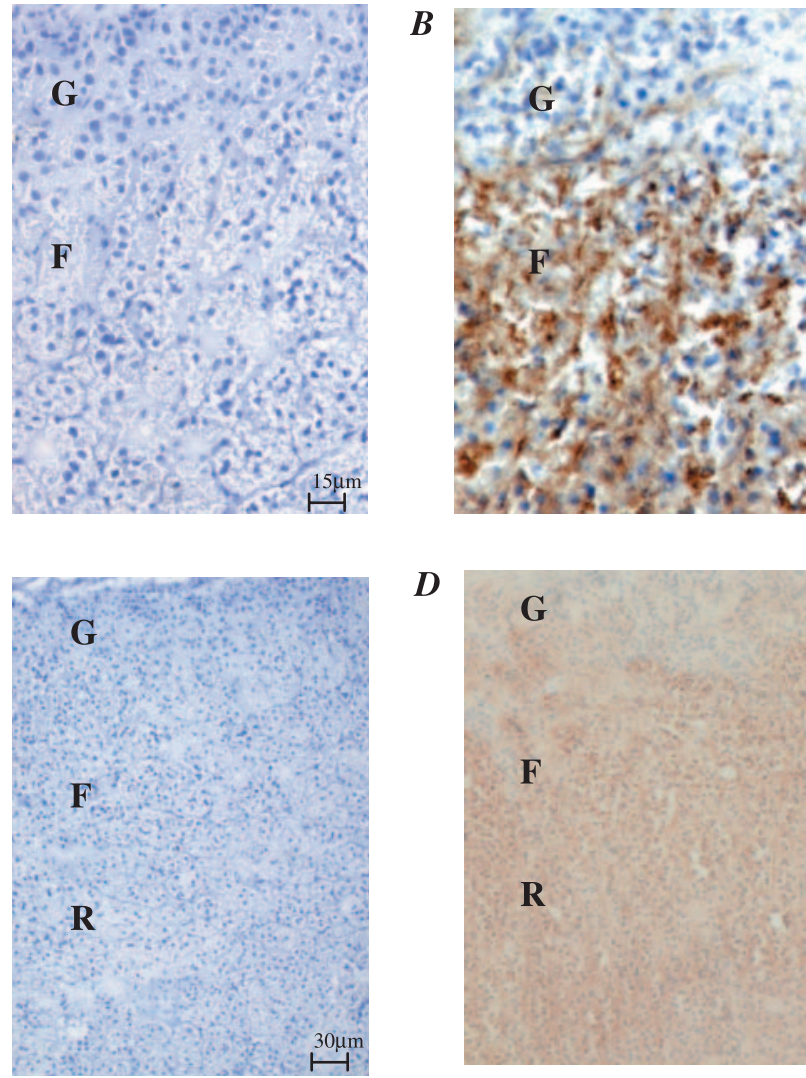

$D$

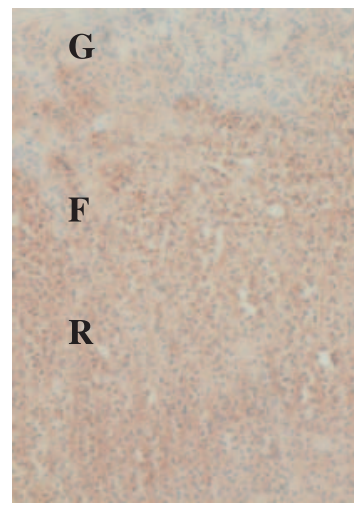

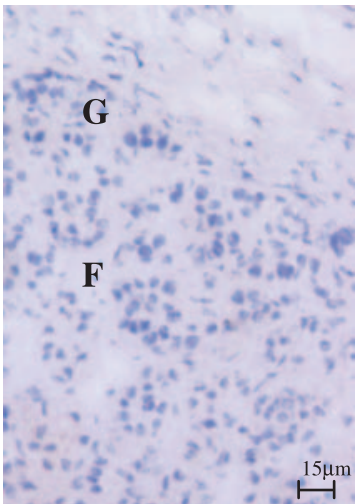

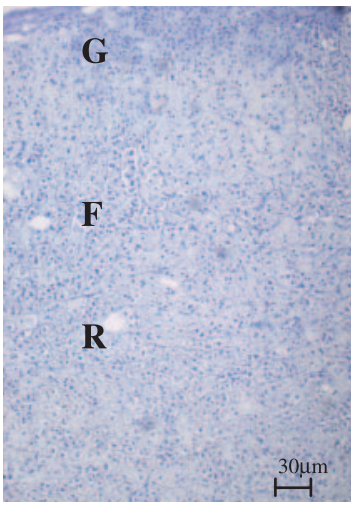

Figure 1 Immunohistochemical localisation of (A and C) SRC-1 and (B and D) SMRT counterstained with haematoxylin (left) and matched IgG-negative controls (right) in human adrenal gland tissue. Positive cells are indicated by a brown stain. $G$, glomerulosa; $F$, fasciculata; $R$, reticularis.

\section{Colocalisation of SF-1 and nur77 with coregulatory proteins}

Given the evidence that SRC-1 and SMRT interact directly with nuclear receptors, the coregulatory proteins would be expected to be expressed in the same cell as the transcription factors, SF-1 and nur77. Immunofluorescence staining was undertaken to confirm subcellular localisation of SRC-1 and SMRT and to identify coexpression with SF-1 and nur77 (Fig. 2). Negative controls were performed where the primary antibody was substituted with matched IgG and no staining was observed (data not shown). SRC-1 and SMRT were found to be expressed in the nucleus and, to a lesser extent, in the cytoplasm of adrenocortical cells. Though the transcription factors and coregulatory proteins were expressed independently, both SRC-1 and SMRT were found to be colocalised with SF-1 and nur77 within a subset of cells in the human adrenal gland (Fig. 2).

\section{Regulation of SF-1 and nur77 $m$ RNA in the H295R cell line}

We have previously shown that SF-1 and nur77 protein expression can be regulated by forskolin and AII. To examine whether these secretagogues have a similar effect at a transcriptional level we assessed the changes in mRNA expression of the transcription factors. SF-1 mRNA was expressed under basal conditions. Following treatment with forskolin an increase in SF-1 mRNA expression was observed. There was no increase in SF-1 mRNA expression in the presence of AII. Nur77 mRNA expression was absent at a basal level but was induced in the presence of forskolin and in particular AII (Fig. $3 A$ and $B$ ).

Regulation of SRC-1 and SMRT $m R N A$ expression in the H295R cell line

The ability of forskolin and AII to regulate SRC-1 and SMRT mRNA following 16, 20 and $24 \mathrm{~h}$ of incubation was examined. Under basal conditions, mRNA expression of SRC-1 and SMRT was low. Treatment with forskolin caused an increase in SRC-1 mRNA expression at all time-points compared with basal levels, with maximal increase seen at $16 \mathrm{~h}$. Following treatment with AII, SRC1 mRNA expression reached a maximum at $20 \mathrm{~h}$. SMRT mRNA expression remained low in the presence of both secretagogues with a small increase in SMRT 


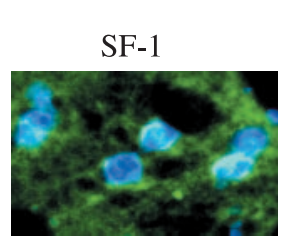

SRC-1

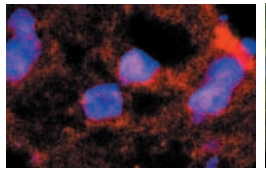

SF-1 \& SRC-1

SF-1

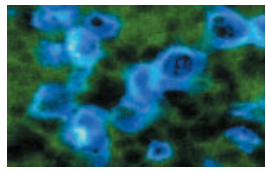

SMRT
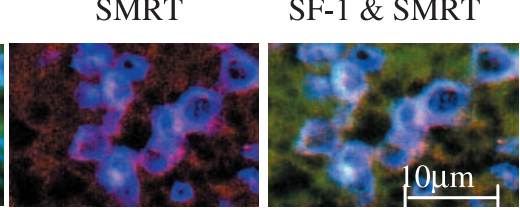

Nur77

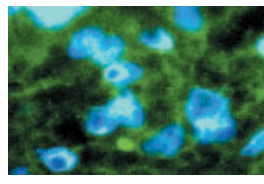

Nur77
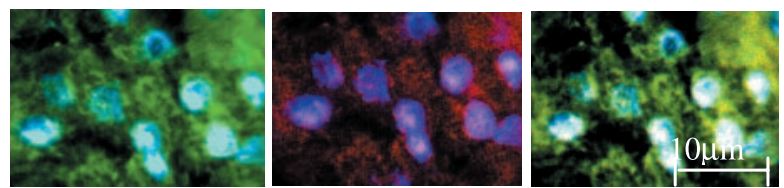

Figure 2 Immunofluorescent colocalization of SF-1 with SRC-1, SF-1 with SMRT, Nur77 with SRC-1 and Nur77 with SMRT in the zona fasciculata of the human adrenal gland tissue. Sections were counterstained with DAPI to identify the nucleus.

mRNA transcripts seen at $24 \mathrm{~h}$ following treatment with forskolin (Fig. 3C and D).

\section{SF-1 and nur 77 binding and recruitment of SRC-1 and} SMRT

To determine the ability of SF-1 and nur77 to bind to their respective response elements in the presence of forskolin and AII and, once bound, to identify SRC-1 and SMRT in the transcription factor-DNA complex, gel shift analysis were performed. Using published oligonucleotide sequences that incorporate the native human CYP17 (for SF-1 binding) and CYP21 (for nur77 binding) (Wilson et al. 1991, Hanley et al. 2001), the ability of nuclear extracts from unstimulated H295R cells to bind to the DNA-binding motif was compared with cells treated with forskolin and AII. DNA protein binding was induced in the presence of both secretagogues at the response element for SF-1 and nur77, in particular AII induced protein interaction at the nur77 response element (NBRE) (Fig. 4). A supershift induced by preincubation of nuclear extracts with anti-SF-1 and anti-nur77 established that these transcription factors were present in the proteinDNA complex. The presence of the coregulatory proteins
(A) SF-1

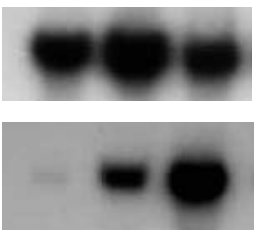

(B) nur77

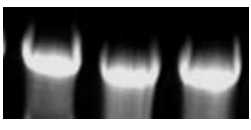

Control Forsk AII

(C) SRC-1

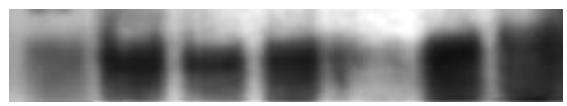

(D) SMRT

$28 S$

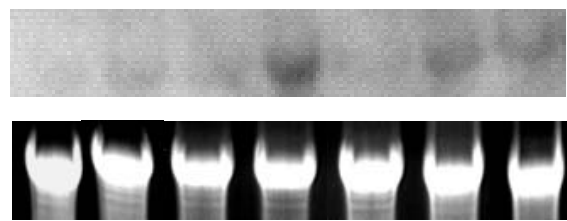

Control $\quad$\begin{tabular}{lllllll}
$16 \mathrm{~h}$ & $20 \mathrm{~h}$ & $24 \mathrm{~h}$ & $16 \mathrm{~h}$ & $20 \mathrm{~h}$ & $24 \mathrm{~h}$ \\
\hline
\end{tabular}

Forskolin

AII

Figure 3 Representative Northern blot of $(A)$ SF-1 and $(B)$ nur77 mRNA expression in the H295R cells following $24 \mathrm{~h}$ of stimulation with $10^{-7} \mathrm{M}$ forskolin (Forsk) and $10^{-7} \mathrm{M}$ All. Representative Northern blot of (C) SRC-1 and (D) SMRT mRNA expression in the H295R cells over a 16, 20 and $24 \mathrm{~h}$ time-course following stimulation with $10^{-7} \mathrm{M}$ forskolin and $10^{-7} \mathrm{M}$ All. The presence and integrity of the $28 \mathrm{~S}$ major RNA component for each lane was examined and found to be similar.

was investigated by preincubation with antibodies directed against SRC-1 and SMRT. SRC-1 was found to be recruited to the SF-1 response element in the presence of forskolin and to the NBRE under basal conditions and in particular in the presence of AII. Conversely, the corepressor SMRT was recruited to the SF-1 response element primarily in the presence of AII and to a lesser extent forskolin, and to the NBRE in the presence of forskolin (Fig. 4).

The ability of the response elements to differentially recruit SRC-1 and SMRT in the presence of AII and forskolin was confirmed by coimmunoprecipitation. SF-1 interacted with SRC-1 in the presence of forskolin but not AII, whereas AII but not forskolin induced SF-1-SMRT interactions. Conversely, nur77 preferentially interacted with SRC-1 in the presence of AII and forskolin induced nur77-SMRT interactions (Fig. 5).

\section{Discussion}

Specific regulation of the adrenal steroids cortisol and adrenal androgen is achieved in part through the 


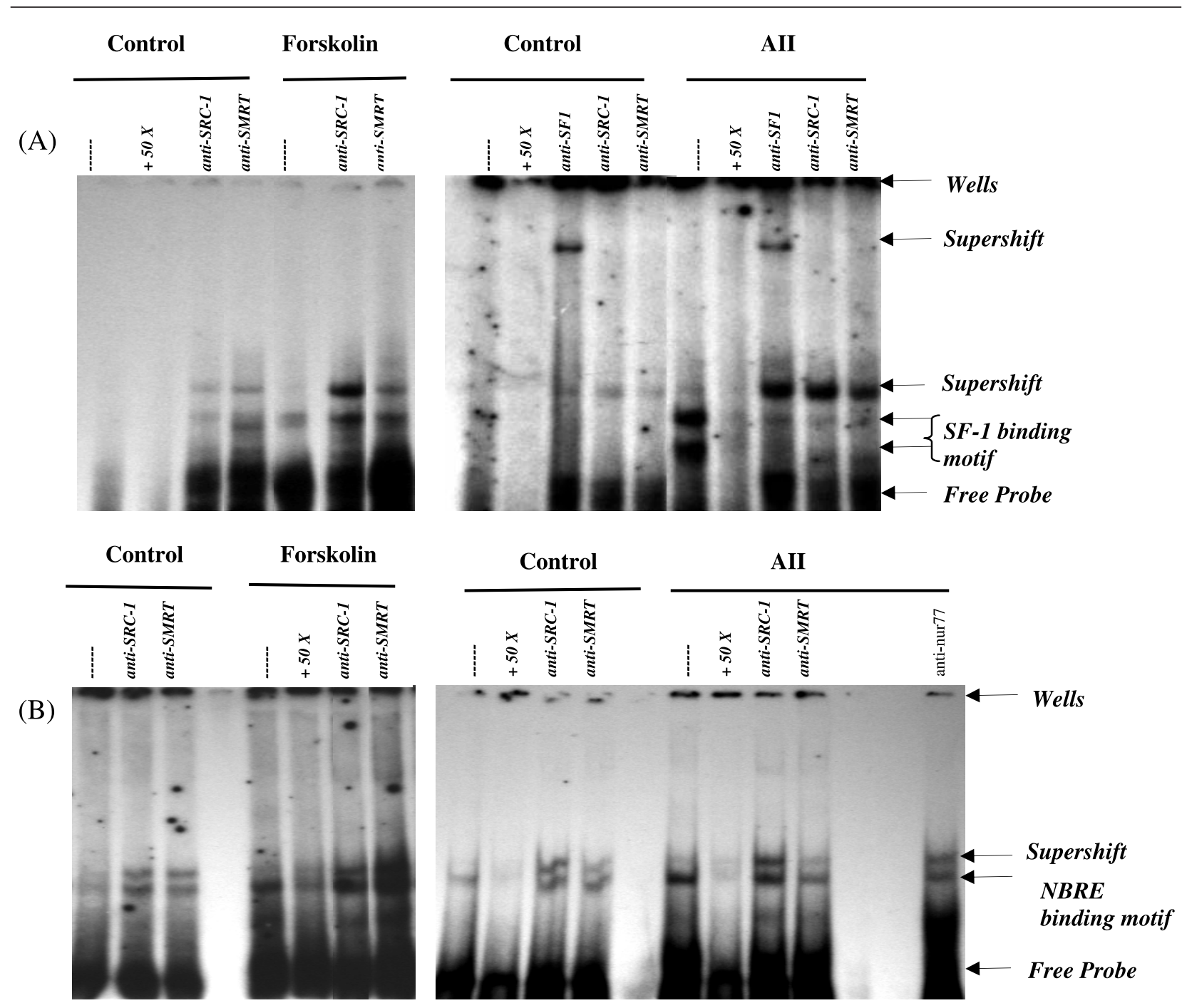

Figure 4 Electrophoretic mobility shift analysis of nuclear extracts from H295R cells. Nuclear protein extracts from H295R cells in the presence and absence of forskolin $\left(10^{-7} \mathrm{M}\right)$ and All $\left(10^{-7} \mathrm{M}\right)$ were compared for increased binding to $(\mathrm{A})\left[\alpha^{32} \mathrm{P}\right] \mathrm{dCTP}-\mathrm{labelled}$ SF-1 response element and (B) $\left[\alpha^{32} \mathrm{P}\right] \mathrm{dCTP}$-labelled NBRE. DNA protein interactions were assayed in the presence of $50 \times$ molar excess of homologous oligonucleotide (+50X). Nuclear protein extracts were preincubated in the presence of anti-SF-1, -SRC-1, -SMRT or -nur 77 . Results are representative of those obtained in three separate experiments.

differential expression of key steroidogenic enzymes, under the influence of secretagogues (Hu et al. 2001b). In the last 10 years studies have shown that the transcription factor SF-1 participates in the expression of all steroidogenic enzymes in the adrenal cortex (Leers-Sucheta et al. 1997, Hu et al. 2001a, Bassett et al. 2002, Sewer \& Waterman 2002). We have previously shown that ACTH and AII can specifically regulate CYP21 by signalling through nur77 (Kelly et al. 2004), signalling through discrete transcription factors may therefore enable the differential regulation of key steroidogenic enzymes. More recently, nerve growth factor inducible $\beta$ has been further implicated in cortisol production through its ability to increase the mRNA expression of $3 \beta$-hydroxysteroid dehydrogenase (Bassett et al. 2004).

Orphan nuclear receptors activate their target gene transcription through interaction with coactivators and corepressors that link receptors to the transcriptional machinery (McKenna et al. 1999a). SF-1 has been previously shown to interact with numerous coactivators such as SRC-1 (Ito et al. 1998), nuclear receptor interacting protein 1 (Zhou et al. 2000), TIF-2 and p/CIP (Hammer et al. 1999, Borud et al. 2002). These interactions, independent of endogenous ligand, are dependent on the activation function $2(\mathrm{AF}-2)$ and have been implicated in the transduction of cAMP signal (Val et al. 2003). To date, 
$S F-1$ interaction with $S R C-1$

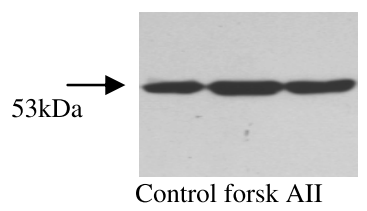

Nur77 interaction with SRC-1

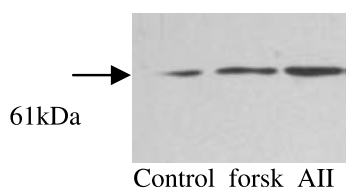

SF-1 interaction with SMRT

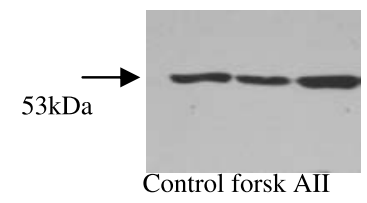

Nur77 interaction with SMRT

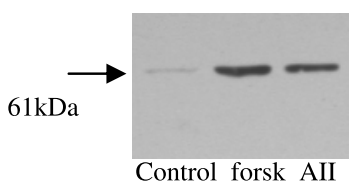

Figure 5 The ability of SF-1 and nur77 to differentially recruit SRC-1 and SMRT was determined by coimmunoprecipitation of the coregulators SRC-1 and SMRT with the transcription factors SF-1 and nur77. Cell lysates were immunopreciptated with either anti-SRC-1 or anti-SMRT and subsequently immunoblotted with anti-SF-1 or anti-nur77. Results are representative of those obtained in three separate experiments. forsk, forskolin.

the only coregulatory proteins to interact with nur77 that have been identified are activating signal cointegrator 2, p160 proteins and SMRT. Unlike SF-1 and most other nuclear receptors AF-2 is thought not to be crucial for nur77 transactivation (Wansa et al. 2002). To date, there is little information regarding the recruitment and potential functional role of SRC-1 and SMRT in the adrenal gland. We propose that, in the adrenal, SF-1 and nur77 can differentially interact with specific coregulatory proteins in the presence of forskolin and AII. In this study, we have investigated the recruitment of coregulatory proteins SRC-1 and SMRT to orphan nuclear receptor response elements and determined secretagogue-dependent interactions with SF-1 and nur77.

The mechanisms behind the differential choice of cofactor recruitment by different nuclear receptors are not known, although different expression profiles of the cofactors in different cell types has been suggested to be essential in cofactor recruitment preferences (Wansa et al. 2002). There have been conflicting reports regarding the subcellular localisation of coregulators. SRC- 1 has been reported to be localised either in the nucleus (Nazareth et al. 1999, Stenoien et al. 2001) or in the cytoplasm (Chen et al. 2001), depending on the cell type and whether it is endogenous or transfected. The present study represents the first immunohistochemical attempt to elucidate the localisation of coregulators SRC-1 and SMRT in the human adrenal gland. Both SRC-1 and SMRT were localised primarily within the nuclei of the human adrenal cortex. Both coregulatory proteins were expressed in the zona fasciculata and zona reticularis but were absent from the zona glomerulosa. Subcellular localisation and dynamic movements of transcription factors has been shown to be one of the primary methods of regulating their transcriptional activity. Given the ability of SRC-1 and SMRT to interact directly with steroid receptors, we expected that these coregulatory proteins would be expressed in the same cells as SF-1 and nur77. SF-1 has recently been colocalised with the coactivators general control of aminoacid synthesis 5-like 2 (yeast)/transformation/transcription domain associated protein in KGN cells following stimulation of the protein kinase A (PKA) pathway with forskolin (Fan et al. 2004). In this study, both SRC-1 and SMRT were coexpressed with both nur77 and SF-1 in the human adrenal cortex. These data suggested that transcription factors may assemble in the nucleus with an accompanying recruitment of coregulatory proteins, SRC-1 and SMRT, and therefore may have a potential role on the functional expression of SF-1 and nur77 target genes in adrenal steroid biosynthesis.

In line with other studies, we have previously shown that forskolin and AII can regulate the protein expression of SF-1 and nur77 (Enyeart et al. 1996, Kelly et al. 2004). The mRNAs encoding several members of the steroid hormone receptor family have been shown either to increase or decrease in response to treatment with their cognate hormones (Misiti et al. 1998). We studied the mRNA expression of orphan nuclear receptors SF-1 and nur77 following treatment with forskolin and AII. Although both their corresponding mRNAs were induced 
by these secretagogues, forskolin was clearly more effective at increasing SF-1 while AII induced larger increases in nur77 mRNA. SF-1 was present in unstimulated cells confirming its constitutive expression, whereas nur 77 was not present at a basal level. We next addressed whether coregulatory mRNA levels are hormonally regulated. There has been marked variation in the tissue-specific expression and differential hormonal regulation of the mRNAs encoding SRC-1 and SMRT described in the literature (Misiti et al. 1998). Oestradiol ( $\left.\mathrm{E}_{2}\right)$ downregulates SRC-1 expression in the rat pituitary gland and up-regulates it in breast cancer cells (Thenot et al. 1999). In contrast, SRC-1 mRNA levels have been reported to be insensitive to $E_{2}$ in the uterus of the rat. SMRT mRNA expression is reported to be low and unchanged after secretagogue stimulation (Nephew et al. 2000). In this study, we found low levels of SRC- 1 mRNA in untreated cells; however, in the presence of forskolin or AII, SRC-1 mRNA levels were increased. In contrast, SMRT mRNA was absent under basal conditions and no significant changes were observed following stimulation in the H295R cells. These results are in accordance with the theory that different cell types have different relative compositions of these coregulators associated with nuclear receptors.

Treatment of adrenocortical cells with forskolin and AII induced binding of SF-1 and nur77 to their respective response elements. A dual binding motif was observed for SF-1, in particular in the presence of AII. Sewer et al. (2002) have demonstrated similar findings where they observed multiple bands resulting at the SF-1 response element in the promoter of CYP17. We determined the ability of forskolin and AII to differentially recruit SRC-1 and SMRT to the DNA-binding elements of SF-1 and to the NBRE and looked at the ability of secretagogues to induce transcription factor coregulatory protein interaction. SRC-1 and SMRT were not present at the SF-1 response element under basal conditions. Binding and recruitment of SRC-1 to SF-1 was induced in the presence of forskolin, whereas in the presence of AII and, to a lesser extent, forskolin, corepressor binding was observed. In line with this, forskolin induced SRC-1SF-1 interactions and AII induced moderate interactions between SMRT and SF-1. In vitro, SF-1-SRC-1 interactions have been previously described (Crawford et al. 1997); however, direct interaction between SF-1 and SMRT are thought not to occur (Ito et al. 1998). SF-1 may therefore recruit SMRT by heterodimerising with other nuclear receptors in a similar manner to its recruitment of the corepressor nuclear co-repressor (Crawford et al. 1998).

Both SRC-1 and SMRT were observed at the nur77DNA complex under control conditions. AII, but not forskolin, induced SRC-1 recruitment to the NBRE and initiated nur77 and SRC-1 interactions. Conversely, SMRT recruitment to the NBRE and transcription factor interactions were seen when cells were treated with forskolin. Previous studies have shown that PKA-induced recruitment of SRC-1 occurs exclusively to nur dimers at the nur response element (Maira et al. 2003). Nur77, however, binds an NBRE site in the promoter region of 21-hydroxylase as a monomer (Wilson et al. 1993), which may explain the poor forskolin induction of SRC-1 recruitment reported here. Forskolin-induced nur77 signalling may therefore be through the recruitment of alternative coactivator proteins. In contrast, AII-induced SRC-1 recruitment and binding to the NBRE suggests that the protein kinase $\mathrm{C}$ pathway may promote monomeric transactivation of nur77 target genes.

Overall, these results have described differential expression and regulation of coregulatory proteins in the adrenal gland. In this study, the ACTH mimetic forskolin induced interactions between the SF-1-DNA complex in the promoter region of CYP-17 and the coactivator SRC-1, and conversely recruited the corepressor SMRT to the NBRE response element in the promoter of CYP21. By contrast, AII induced SRC-1-nur77 interactions and SMRT recruitment to SF-1. These data provide evidence that secretagogues can utilise coregulatory proteins to discretely regulate expression of key steroidogenic enzymes in the human adrenal cortex.

\section{Acknowledgements}

We are very grateful to Professor R M Evans, Salk Institute for Biological Studies for his generous gift of SMRT cDNA. This work was supported by the Health and Research Board of Ireland and Enterprise Ireland. The authors declare that there is no conflict of interest that would prejudice the impartiality of this scientific work.

\section{References}

Auger AP, Tetel MJ \& McCarthy MM 2000 Steroid receptor coactivator-1 (SRC-1) mediates the development of sex-specific brain morphology and behavior. PNAS 97 7551-7555.

Bassett MH, Zhang Y, Clyne C, White PC \& Rainey WE 2002 Differential regulation of aldosterone synthase and 11 beta-hydroxylase transcription by steroidogenic factor-1. Journal of Molecular Endocrinology 28 125-135.

Bassett MH, Suzuki T, Sasano H, De Vries CJ, Jimenez PT, Carr BR \& Rainey WE 2004 The orphan nuclear receptor NGFIB regulates transcription of 3 beta-hydroxysteroid dehydrogenase. Implications for the control of adrenal functional zonation. Journal of Biological Chemistry 279 37622-37630.

Borud B, Hoang T, Bakke M, Jacob AL, Lund J \& Mellgren G 2002 The nuclear receptor coactivators $\mathrm{p} 300 / \mathrm{CBP} /$ cointegrator-associated protein $(\mathrm{p} / \mathrm{CIP})$ and transcription intermediary factor 2 (TIF2) differentially regulate PKA-stimulated transcriptional activity of steroidogenic factor 1. Molecular Endocrinology 16 757-773.

Chen SL, Wang SC, Hosking B \& Muscat GE 2001 Subcellular localization of the steroid receptor coactivators (SRCs) and MEF2 in muscle and rhabdomyosarcoma cells. Molecular Endocrinology 15 783-796. 
Crawford PA, Polish JA, Ganpule G \& Sadovsky Y 1997 The activation function-2 hexamer of steroidogenic factor-1 is required, but not sufficient for potentiation by SRC-1. Molecular Endocrinology 11 1626-1635.

Crawford PA, Dorn C, Sadovsky Y \& Milbrandt J 1998 Nuclear receptor DAX-1 recruits nuclear receptor corepressor N-CoR to steroidogenic factor 1. Molecular and Cellular Biology 18 2949-2956.

Enyeart JJ, Boyd RT \& Enyeart JA 1996 ACTH and AII differentially stimulate steroid hormone orphan receptor mRNAs in adrenal cortical cells. Molecular and Cellular Endocrinology 124 97-110.

Fan W, Yanase T, Wu Y, Kawate H, Saitoh M, Oba K, Nomura M, Okabe T, Goto K, Yanagisawa J et al. 2004 Protein kinase A potentiates adrenal 4 binding protein/steroidogenic factor 1 transactivation by reintegrating the subcellular dynamic interactions of the nuclear receptor with its cofactors, general control nonderepressed-5/transformation/transcription domain-associated protein, and suppressor, dosage-sensitive sex reversal-1: a laser confocal imaging study in living KGN cells. Molecular Endocrinology 18 127-141.

Gregory CW, Wilson EM, Apparao KB, Lininger RA, Meyer WR, Kowalik A, Fritz MA \& Lessey BA 2002 Steroid receptor coactivator expression throughout the menstrual cycle in normal and abnormal endometrium. Journal of Clinical Endocrinology and Metabolism 87 2960-2966.

Hammer GD, Krylova I, Zhang Y, Darimont BD, Simpson K, Weigel NL \& Ingraham HA 1999 Phosphorylation of the nuclear receptor SF-1 modulates cofactor recruitment: integration of hormone signaling in reproduction and stress. Molecular Cell 3 521-526.

Hanley NA, Rainey WE, Wilson DI, Ball SG \& Parker KL 2001 Expression profiles of SF-1, DAX1, and CYP17 in the human fetal adrenal gland: potential interactions in gene regulation. Molecular Endocrinology 15 57-68.

Horlein AJ, Naar AM, Heinzel T, Torchia J, Gloss B, Kurokawa R, Ryan A, Kamei Y, Soderstrom M, Glass CK et al. 1995 Ligand-independent repression by the thyroid hormone receptor mediated by a nuclear receptor co-repressor. Nature 377 397-404.

Horwitz KB, Jackson TA, Bain DL, Richer JK, Takimoto GS \& Tung L 1996 Nuclear receptor coactivators and corepressors. Molecular Endocrinology 10 1167-1177.

Hu MC, Hsu NC, Pai CI, Wang CK \& Chung B 2001a Functions of the upstream and proximal steroidogenic factor 1 (SF-1)-binding sites in the CYP11A1 promoter in basal transcription and hormonal response. Molecular Endocrinology 15 812-818.

Hu MC, Chiang EF, Tong SK, Lai W, Hsu NC, Wang LC \& Chung BC $2001 b$ Regulation of steroidogenesis in transgenic mice and zebrafish. Molecular and Cellular Endocrinology 171 9-14.

Ito M, Yu RN \& Jameson JL 1998 Steroidogenic factor-1 contains a carboxy-terminal transcriptional activation domain that interacts with steroid receptor coactivator-1. Molecular Endocrinology 12 290-301.

Kelly SN, McKenna TJ \& Young LS 2004 Modulation of steroidogenic enzymes by orphan nuclear transcriptional regulation may control diverse production of cortisol and androgens in the human adrenal. Journal of Endocrinology 181 355-365.

Leers-Sucheta S, Morohashi K, Mason JI \& Melner MH 1997 Synergistic activation of the human type II 3 beta-hydroxysteroid dehydrogenase/delta5-delta4 isomerase promoter by the transcription factor steroidogenic factor-1/adrenal 4-binding protein and phorbol ester. Journal of Biological Chemistry 272 7960-7967.

McKenna TJ \& Cunningham SK 1991 The control of adrenal androgen secretion. Journal of Endocrinology 129 1-3.

McKenna NJ, Lanz RB \& O'Malley BW 1999a Nuclear receptor coregulators: cellular and molecular biology. Endocrine Reviews $\mathbf{2 0}$ 321-344.

McKenna NJ, Xu J, Nawaz Z, Tsai SY, Tsai MJ \& O’Malley BW $1999 b$ Nuclear receptor coactivators: multiple enzymes, multiple complexes, multiple functions. Journal of Steroid Biochemistry and Molecular Biology 69 3-12.
Maira M, Martens C, Batsche E, Gauthier Y \& Drouin J 2003 Dimer-specific potentiation of NGFI-B (Nur77) transcriptional activity by the protein kinase A pathway and AF-1-dependent coactivator recruitment. Molecular and Cellular Biology 23 763-776.

Misiti S, Schomburg L, Yen PM \& Chin WW 1998 Expression and hormonal regulation of coactivator and corepressor genes. Endocrinology 139 2493-2500.

Nazareth LV, Stenoien DL, Bingman WE 3rd, James AJ, Wu C, Zhang Y, Edwards DP, Mancini M, Marcelli M, Lamb DJ et al. 1999 A C619Y mutation in the human androgen receptor causes inactivation and mislocalization of the receptor with concomitant sequestration of SRC-1 (steroid receptor coactivator 1). Molecular Endocrinology 13 2065-2075.

Nephew KP, Ray S, Hlaing M, Ahluwalia A, Wu SD, Long X, Hyder SM \& Bigsby RM 2000 Expression of estrogen receptor coactivators in the rat uterus. Biology of Reproduction 63 361-367.

Parker KL \& Schimmer BP 1994 The role of nuclear receptors in steroid hormone production. Seminars in Cancer Biology 5 317-325.

Sewer MB \& Waterman MR 2002 Transcriptional complexes at the CYP17 CRS. Endocrine Research 28 551-558.

Sewer MB, Nguyen VQ, Huang CJ, Tucker PW, Kagawa N \& Waterman MR 2002 Transcriptional activation of human CYP17 in H295R adrenocortical cells depends on complex formation among p54(nrb)/NonO, protein-associated splicing factor, and $\mathrm{SF}-1$, a complex that also participates in repression of transcription. Endocrinology 143 1280-1290.

Sohn YC, Kwak E, Na Y, Lee JW \& Lee SK 2001 Silencing mediator of retinoid and thyroid hormone receptors and activating signal cointegrator-2 as transcriptional coregulators of the orphan nuclear receptor Nur77. Journal of Biological Chemistry 276 43734-43739.

Spencer TE, Jenster G, Burcin MM, Allis CD, Zhou J, Mizzen CA, McKenna NJ, Onate SA, Tsai SY, Tsai MJ et al. 1997 Steroid receptor coactivator-1 is a histone acetyltransferase. Nature 389 194-198.

Stenoien DL, Patel K, Mancini MG, Dutertre M, Smith CL, O'Malley BW \& Mancini MA 2001 FRAP reveals that mobility of oestrogen receptor-alpha is ligand- and proteasome-dependent. Nature Cell Biology 3 15-23.

Sterner DE \& Berger SL 2000 Acetylation of histones and transcription-related factors. Microbiology and Molecular Biology Reviews 64 435-459.

Thenot S, Charpin M, Bonnet S \& Cavailles V 1999 Estrogen receptor cofactors expression in breast and endometrial human cancer cells. Molecular and Cellular Endocrinology 156 85-93.

Val P, Lefrancois-Martinez AM, Veyssiere G \& Martinez A 2003 SF-1 a key player in the development and differentiation of steroidogenic tissues. Nuclear Receptor 18.

Wansa KD, Harris JM \& Muscat GE 2002 The activation function-1 domain of Nur77/NR4A1 mediates trans-activation, cell specificity, and coactivator recruitment. Journal of Biological Chemistry 277 33001-33011.

Wieser F, Schneeberger C, Hudelist G, Singer C, Kurz C, Nagele F, Gruber C, Huber JC \& Tschugguel W 2002 Endometrial nuclear receptor co-factors SRC-1 and N-CoR are increased in human endometrium during menstruation. Molecular Human Reproduction $\mathbf{8}$ 644-650.

Wilson TE, Fahrner TJ, Johnston M \& Milbrandt J 1991 Identification of the DNA binding site for NGFI-B by genetic selection in yeast. Science 252 1296-1300.

Wilson TE, Fahrner TJ \& Milbrandt J 1993 The orphan receptors NGFI-B and steroidogenic factor 1 establish monomer binding as a third paradigm of nuclear receptor-DNA interaction. Molecular and Cellular Biology 13 5794-5804.

Winterer J, Gwirtsman HE, George DT, Kaye WH, Loriaux DL \& Cutler GB Jr 1985 Adrenocorticotropin-stimulated adrenal 
androgen secretion in anorexia nervosa: impaired secretion at low weight with normalization after long-term weight recovery. Journal of Clinical Endocrinology and Metabolism 61 693-697.

Xu L, Glass CK \& Rosenfeld MG 1999 Coactivator and corepressor complexes in nuclear receptor function. Current Opinion in Genetics and Development 9 140-147.

Xu J, Liao L, Ning G, Yoshida-Komiya H, Deng C \& O'Malley BW 2000 The steroid receptor coactivator SRC-3

(p/CIP/RAC3/AIB1/ACTR/TRAM-1) is required for normal growth, puberty, female reproductive function, and mammary gland development. PNAS 97 6379-6384.
Zhou D, Quach KM, Yang C, Lee SY, Pohajdak B \& Chen S 2000 PNRC: a proline-rich nuclear receptor coregulatory protein that modulates transcriptional activation of multiple nuclear receptors including orphan receptors SF1 (steroidogenic factor 1) and ERRalpha1 (estrogen related receptor alpha-1). Molecular Endocrinology 14 986-998.

Received 4 April 2005

Accepted 28 April 2005 